\title{
Inventing the Neolithic? Putting evidence-based interpretation back into the study of faunal remains from causewayed enclosures.
}

Pip C.R. Parmenter, Emily V. Johnson and Alan K. Outram

Department of Archaeology, University of Exeter, North Park Road, Exeter, EX4 4QE.

\section{Abstract}

The paper argues that our current understanding of the animal bones from causewayed enclosure sites in Britain is flawed. During the 1980-90s, a number of key interpretations, still frequently espoused, were based more upon anecdote and theory-driven assertion than on empirical evidence. An example is that evidence of bone processing (butchery and bone fracture) does not feature heavily in the faunal record from causewayed enclosures. Using data from the sites of Etton and Staines, this view must now be questioned. Both butchery and peri-mortem bone fracture are present in these assemblages in substantial quantities. These sites are compared with Ludwinowo 7, a Linearbandkeramik settlement site in Poland and there are considerable similarities between the three different sites. This suggests possibility that the broader economic utility of animal bone assemblages at causewayed enclosures has been underestimated, having been, up to now, regarded as 'not indicative of domestic settlement'.

Keywords: Neolithic, causewayed enclosures, LBK, Linearbandkeramik, faunal remains, bones, fracture, butchery

\section{Introduction}

This paper presents the results of investigations into the types of bone processing present at two causewayed enclosure sites in Britain, Etton and Staines, and an LBK settlement site in Poland - Ludwinowo 7. The analysis of the material from Etton and Staines is the first of its kind to be carried out on causewayed enclosures in Britain (Parmenter 2015), and the analysis of the material from Ludwinowo 7 is part of an ongoing project to understand the relationship between levels of dairying and other forms of animal exploitation in the LBK (NEOMILK ERC324202).

The Etton causewayed enclosure is located in Maxey, Cambridgeshire. It was excavated over five years in the 1980s in advance of quarrying activity. The excavations were directed by Francis Pryor and remain one of the most complete excavations of an enclosure ditch and interior of a causewayed enclosure ever carried out (Pryor 1998). The assemblage of animal bones from the site is large and extremely well preserved, making it ideal for the first detailed study into bone 
processing at causewayed enclosures. Miranda Armour-Chelu reported on the animal bones in the original site monograph, however, this analysis has recently been shown to be incomplete (Parmenter 2015). The Staines causewayed enclosure was excavated in the 1960s prior to gravel extraction. It is located roughly under the present day junction 13 of the M25. The surviving animal bone assemblage is relatively small compared to Etton, and not so well preserved. However, the site itself is often compared to Etton as being of comparable size and type (Pryor 1998).

The Linearbandkeramik (LBK) settlement of Ludwinowo 7 is located in the Kuyavia region of central Poland, situated on the edge of a small elongated plateau. The soil type is not the familiar loess that is typical of LBK settlements, but instead an equally fertile heavy gley soil (Pyzel 2012, 160). A planned motorway resulted in a rescue excavation of a fragment of the site, which revealed 13 or 14 longhouses along with other features such as clay pits and pits (Pyzel 2012, 161). The earliest traces of occupation on the site date to Kuyavian phase I, the late älteste LBK, with the main inhabitation of the site in the Kuyavian phase Ila (or the Notenkopf), until Kuyavian phase III (Pyzel 2012, 162). The majority of the bones presented in this paper were recovered from the later phases of activity.

The current work being conducted into bone processing at LBK sites has allowed for a direct comparison between causewayed enclosure sites in Britain, which have not, in recent years at least, tended to be regarded as containing evidence of domestic settlement activity; and sites in Europe, which have always been seen as domestic settlements. It is a widely held belief that the animal bone at British causewayed enclosures cannot be representative of the more general domestic Neolithic economy, given that their function is in no way domestic. However, as this paper demonstrates, a comparison with LBK settlements shows that in fact there is little distinction between the bone assemblages from the two types of site. This empirical evidence can be used to begin to counter the arguments that animal bone at causewayed enclosures is somehow not what we would expect to see at domestic settlements, and directly contradicts assertions regarding the nature of Neolithic animal bone assemblages that have been made and widely disseminated over the past decades.

\section{Inventing the Neolithic?}

'It is evident that the consumption of large quantities of meat took place at various kinds of monuments during the Neolithic. At none of these [Neolithic monuments] is 
there extensive evidence for complex bone-processing, marrow-splitting and butchery marks... More clear traces of bone processing might be expected if the nutritional value of the carcasses were being exploited to the full.'

(Thomas 1999, 27).

The above quote is from Julian Thomas' seminal book 'Rethinking the Neolithic'. It is taken from a passage in which he argues against the notion that the animal bone remains present at causewayed enclosure sites are generally representative of the everyday economy of the Neolithic. Rather, he believes that the animal bones present at causewayed enclosures represent 'special' or 'ritual' occasions, large feasting events the remains of which were placed within the ditches of causewayed enclosures in a way which was planned and purposeful and which was intended to invoke memories of pertinent celebrations - rites of passage, fertility rituals and the like. These notions have become widely prevalent within the literature pertaining to the British Neolithic and in particular to causewayed enclosure sites (Oswald et al. 2001; Pollard 2001; Whittle 2003; Harris 2003).

One of the main reasons for Thomas believing that the faunal assemblages from causewayed enclosure sites are not representative of the more mundane Neolithic economy is the purported fact that the animal bone is not being processed to the extent that one would expect to see if animal carcasses were being exploited to maximum nutritional effect. This point seems to be fair enough, in fact many academics (writing both before and after Thomas) who have studied deposition made similar points with regard to notions of conspicuous consumption and the repeated deposition of articulated bone groups or selections of bone which do not appear to indicate a particular focus on nutrition (Grant 1984; Wait 1985; Edmonds 1999; Gibson 2003; Cunliffe 1992; Whittle et al. 1999; Morris 2008).

'Rethinking the Neolithic' was written when very little work had been undertaken that was directly concerned with 'complex bone processing' on Neolithic sites in Britain, let alone causewayed enclosure sites. One of the few relevant studies was Grigson's (1999) work at Windmill Hill and, whilst this study presents evidence for bone fragmentation, it does not deal with fracture types or provide any comparative frame of reference. Nonetheless, Thomas prematurely claims that 'at none of these [Neolithic monuments] is there extensive evidence for complex bone-processing, marrow-splitting and butchery marks' (Thomas 1999, 27). Clearly, this is something that had not been well studied at the time, yet it is presented as being a feature of the 
British Neolithic, and is used to bolster his later arguments about the ritual use of causewayed enclosures and the state of the Neolithic economy. Even if it were subsequently shown to be true, in the context in which it was written it overstepped the available evidence.

We have outlined above just one area in which significant and often repeated interpretations are based largely upon assertion, but unfortunately bone processing is not the only area in which some authors have downplayed the evidence for the domestic economy in the Neolithic. For example, Thomas and others argue that the farming of cereals was, at best, sporadic with little real importance to the Neolithic economy, and when crops were exploited it was for 'ritual' or 'ceremonial' activity and therefore they do not reflect everyday subsistence (Edmonds 1999; Thomas 1999; 2003; Whittle 2003). These authors also note that there is plenty of evidence for hazelnuts from charred shells and use this to indicate the continued significant of wild foods. This notion is contrary to the opinion that in mainland Europe crops were cultivated as basis of everyday subsistence (Ammerman and Cavallil-Sforza 1971; Bogucki 1998; Lüning 2000). Thomas criticizes Ammerman and Cavalli-Sforza for concentrating their research on the presence of charred cereal grains rather than the impact that cereals would have had on the people of the time (Thomas 2004, 424).

More recently, comparisons between the concentrations of charred cereal evidence from Britain and mainland Europe have shown no significant difference (Bogaard and Jones 2007, 370). Bogaard and Jones have suggested that this is more interesting as an example of the British obsession of divorcing function and ritual than it is of any particular economic system. In this instance the assertions made by Thomas (1999) were made well in advance of the detailed research by Bogaard and Jones (2007). It was, therefore, perfectly reasonable for him to pose the hypothesis that cereals seemed of less economic importance in early Neolithic Britain, but not assert it in the absence of appropriate data or a full understanding of the different taphonomic and site formation processes affecting nut shells and cereals (see Rowley-Conwy 2000; Jones 2000; Jones and Rowley-Conwy 2007 for detailed discussion). Despite ever mounting evidence for significant economic exploitation of cereals in Neolithic Britain, Thomas $(2013,395)$ has refocused his argument away from the cereals themselves, now there is good comparative data for those, towards the part of his original argument that stressed the greater relative presence of wild hazelnuts, for which equivalent comparative data are still not presented. Of course, even if true, the greater relative presence of hazelnuts in Britain in no way reduces the strength of 
evidence for significant economic use of cereals, since the two things are not mutually exclusive. We still eat hazelnuts and wild game today; their presence is interesting, both socially and economically, but is not evidence against developed agriculture.

In general, evidence for domestic food production has been significantly downplayed in relation to early Neolithic Britain, by comparison to continental Europe, even when the nature of the evidence is similar. In 'Understanding the Neolithic' Thomas argues that there is a general disconnection between economic change and material culture (Thomas 1999, 16). He states that "the very sudden cultural change from Mesolithic to Neolithic appears to be superimposed upon a much more long-term cultural shift from food gathering to food production" (Thomas 1999, 16). This theory is illustrated by a graph that shows instant change in material culture upon the arrival of the Neolithic, whilst economic change happens very slowly indeed, only accelerating to full agriculture in the middle Bronze Age (Thomas 1999, Figure 2.1). More recently, Thomas (2013) shows little sign of significantly revising this view.

\section{Bone processing in the Neolithic}

\section{Butchery}

The observation of butchery marks on animal bones from archaeological sites is fairly commonplace. However, the analysis of these marks, at least with reference to Neolithic sites in Britain, is not so widespread. Syntheses of proportions of butchered bones for sites and species, as well as attempts to understand the implications of different types and locations of butchery marks, are something that have only really developed in the past 25 years (Serjeantson 2011, 55). As such, there were few suitable sources to refer to at the time Thomas made his statements on the topic.

Increasing interest in the subject in recent years has brought new evidence to light regarding the intensity of butchery at various Neolithic sites. Serjeantson (2011) lists the few sites in the south of Britain for which overall proportions of butchered bone have been established and appears to suggest that one site in particular, Boscombe Down, is unusual for the high level of butchery visible (9\%). This is in comparison to six other sites at which levels of butchery go no higher than $3.8 \%$. However at Durrington Walls between $10 \%$ and $20 \%$ of the cattle and pig bone shows cut marks and between $60 \%$ and $80 \%$ of the cattle bone appeared to have been chopped, implying that the butchery of animal carcasses was systematic. At the time of writing, Albarella and Serjeantson (2002) were working on Durrington under the impression 
that it was a 'ritual' site and they concluded that the high levels of butchery were the result of intensive episodes of feasting. However, more recent excavations at Durrington have revealed evidence of houses and domestic areas (Parker-Pearson et al. 2008). This does not at all preclude large scale feasting activity, but it does leave cause to consider the distinction between feasting and eating and the role preexisting interpretations of site function had upon the conclusions regarding the faunal assemblage.

The same methodologies for recording butchery were used during our analyses of Etton, Staines and Ludwinowo 7. Incidences of butchery on identifiable specimens were drawn upon bone templates, as well as being described for characteristics such as type (chop, cut, scratch etc.), severity and number of strokes. This methodology provides a direct, unambiguous representation of the position of butchery marks on bone specimens, and allows the butchery events on certain skeletal elements to be presented in unity through layering the data from multiple specimens of the same element. This approach follows the technique used in the analysis of human and animal remains from the Bronze Age site of Velim (see Outram et al. 2005; Harding et al. 2007 for further details).

\section{Marrow and Bone Grease}

Bone processing, in terms of marrow extraction and production of bone grease, has not been discussed with reference to many British Neolithic sites. Given that the majority of sites which have been excavated and from which animal bone assemblages have been recovered are interpreted as having been constructed and used for activities other than general domestic settlement, this is perhaps not surprising. While some level of marrow extraction from cooked bones might be reasonably expected from sites at which large scale feasting and celebrations were occurring (possibly as a by-product of large-scale meat consumption), it is not likely that there would be any evidence for systematic bone processing for either marrow or grease. This activity, especially if it were occurring on uncooked bone, is presumed to be much more likely to be visible on a domestic settlement than in a ritual context.

Much of what we currently understand about Neolithic causewayed enclosures comes from the publication reports for Windmill Hill and Hambledon Hill. Although graphs illustrating the levels of fractured bone are presented in the form of graphs in the Windmill Hill report (Grigson 1999), neither report contains any substantive 
assessment of the implications of the fragmentary assemblage, nor makes any reference to fracture patterns. Curiously, one of the only sites at which the fracture and fragmentation of bones has been considered is Durrington Walls (Albarella and Serjeantson 2002). Here, the argument is made that pig carcasses were subject to less intensive fragmentation than 'normal', where 'normal' is defined by the level of fragmentation at Runnymede, which is reportedly around 98\%, though it is unclear how this number has been reached. Durrington Wall's $80 \%$ fragmentation is claimed to be low in comparison, despite the fact that by the author's admission, shaft splinters were not collected. Marrow extraction has been identified on a 'fair proportion' of bones from Durrington, but exploitation is not thought to have been 'systematic' (Albarella and Serjeantson 2002, 41). This in itself, despite the author's downplaying of the role of fat extraction in favour of a feasting interpretation, contradicts Thomas' (1999) general view that faunal deposits at Neolithic monuments tend not to be substantially related to subsistence activities. As discussed above, when Albarella and Serjeantson published their 2002 paper, the interpretation of the site remained as a ritual centre. With subsequent interpretations suggesting the site was an auxiliary settlement to Stonehenge (Parker-Pearson 2012), it is interesting to wonder whether this downplaying of the fat processing at the site would have occurred, were the animal bones being interpreted with this in mind.

Despite the groundwork that has been done for the use of bone fracture work more generally in zooarchaeology (Johnson 1985; Outram 2001), it remains a poorly understood and underused facet of zooarchaeological study - especially within the context of British archaeology, and more specifically to this investigation, the British Neolithic. This has not prevented such patterns from being alluded to by some authors (Thomas 1999; Albarella and Serjeantson 2002) writing about Neolithic sites, but for the most part any assertion made regarding the absence of evidence for fat extraction and bone processing (and any conclusion reached as a result of this) is based on little empirical evidence.

Incidences of fresh fracture at Etton, Staines and Ludwinowo 7 were identified based on characteristics described by Johnson (1985) and Outram (2001; 2002; et al. 2005). Fresh fracture characteristics are defined as those fractures that display a helical, curving outline, an acute fracture angle to the surface of the bone, and a smooth texture of fracture surface. For all shaft bones and mandibles that displayed evidence of fracture it was determined, based on the above characteristics, whether the bone was fractured when fresh, dry, or when all organic content had been lost 
(mineralized). Bones with multiple fractures were also able to be recorded in this way. 'New' breaks, those made during excavation or curation, were noted but are excluded from the results presented.

\section{Results}

\section{Butchery}

Butchery marks were found to be visible on $10 \%$ of the identifiable bone from the Etton causewayed enclosure. This is considerably more than the $3 \%$ stated in the original report (Armour-Chelu 1998, 274). Of all of the species present at Etton, four were found to have been subject to butchery methods which left the marks of this activity on the surface of the bone - these were the three primary domesticates (cattle, pig and caprines) and red deer. Despite being the least well represented of these species, red deer were found to have the highest prevalence of butchery marks (24\%). This is not surprising, as it is likely that as a hunted species, fairly intensive, but not necessarily careful, field butchery of the red deer carcass would have occurred at the kill site in order to transport the meat back to the Etton. Cattle were the next most highly butchered species, with $18.1 \%$ of the identified elements displaying some evidence for butchery. Pig and ovicaprids followed, with $14 \%$ and $10 \%$ (respectively) of bones having visible evidence of butchery (Figure 1).

At Ludwinowo 7, butchery was visible on $7.4 \%$ of identifiable specimens, and affected the main three domesticates (cattle, ovicaprids and pigs) and wild animals (red deer, aurochs and roe deer). Of the domestic animals, pigs were the most commonly butchered, with $19.6 \%$ of identifiable pig specimens showing butchery marks (Figure 1). Cattle followed at $13.3 \%$ butchered, and ovicaprids at $6.7 \%$. Large wild species showed more intensive butchery than domestic animals despite, as is the case at Etton, being less well represented than any of the domestic species. Aurochs showed butchery marks on $23.3 \%$ of identifiable specimens, red deer on $30 \%$ of identifiable specimens and roe deer on $14.3 \%$ of identifiable specimens. This could again be explained by intensive kill-site butchery of these animals for transport back to the settlement. Arguably this would not have been as necessary on smaller wild animals, such as roe deer, which displayed butchery marks on $14 \%$ of identifiable specimens. Despite the relatively high level of butchery on domestic pigs, the pattern of butchery at Ludwinowo 7 is strikingly similar to that displayed at Etton, especially in the overall proportion of butchered identifiable specimens and the butchery on domestic cattle and large wild animals. 
The notion that feasting is synonymous with the function of causewayed enclosures, henge monuments and funerary monuments is widely accepted with regards to the British Neolithic, and is one of the main lines of evidence used to suggest that causewayed enclosures were the sites of intermittent gatherings, ceremonies and other communal occasions (Parker-Pearson 2003). The deposition of partial skeletons has been associated with feasting activity and although partial skeletons are present at Etton they are far over-shadowed at Etton by the deposition of highly fragmented, intensively processed (butchered and purposely broken) animal bone. Not only this, but although it was difficult to fully understand the nature of the partial skeletons based on the archived material, it was clear that despite being deposited together some (not all) of the groups of bone were not articulated at the time of deposition. Evidence for the disarticulation of animals was also abundant, suggesting that they were heavily portioned. Although feasting activity does not preclude the portioning of animals or meat, it does not traditionally support it.

At the original estimation of $3 \%$ of the bones displaying butchery marks (ArmourChelu 1998, 274), the proportion of butchered bones would have been in line with assemblages from barrow and henge sites such as Coneybury Henge, Down Farm Wyke Down Henge and Seven Barrows Gallop, as well as pits sites like Down Farm Firtree Field and Roughground Farm (see Figure 2 and Serjeantson 2011, 55). With $10 \%$ of the bone showing some kind of butchery, and this total likely to have been more if the bone in the higher levels had not been subject to water logging and surface deterioration, the amount of butchery is much closer to the level seen on the pig remains from Runnymede - an assemblage which has always been identified as being 'domestic' in nature, and those from the Ludwinowo 7.

\section{Fragmentation}

The analysis of the patterns of bone fragmentation at Etton, Staines and Ludwinowo 7 provide possibly the most interesting data from this study. All of the species, both wild and domestic, which are traditionally considered as 'meat-bearing'; cattle, pigs, caprines, aurochs, red deer and roe deer appeared to have been exploited for their bone marrow. This is despite the fact that wild species are only present in extremely small numbers. The remains of dogs, foxes and humans (only present in very small numbers), had no evidence for the exploitation of marrow. This indicates that the helical fractures present throughout the assemblage were at least largely the result of intentional bone breakage for access to the marrow cavity. 
The proportions of helical fracture present at Etton and Staines were both unexpected and extremely interesting. One of the reasons this study was constructed was to test the assertion that helically fractured bone was present in only negligible quantities at causewayed enclosures. The premise of there being no evidence for fresh bone breakage/marrow extraction derived from, and was used to bolster the idea that causewayed enclosures were somehow devoid of settlement or domestic activity. Given this premise was so widely accepted by Neolithic specialists, the fact that at Etton $32.1 \%$ and at Staines $29 \%$ of all identifiable bones appeared to have been fractured when fresh is enough to question the conclusion that there was little bone processing. If this is compared to the LBK settlement of Ludwinowo 7, with $32 \%$ of all identifiable bones displaying fresh fracture, it is clear that there is negligible difference between these site types overall (see Figure 3).

As not all bones are suitable for the extraction of marrow, and some are more suitable than others, it is possible to be more precise with the data in constructing a picture of marrow extraction activity at both Staines and Etton. At Staines almost $60 \%$ of the bones known to yield high quantities of marrow (humerus, radius, femur and tibia) appeared to have been processed for marrow extraction. At Etton around $35 \%$ of high marrow yield bones had been processed. More specifically, at Etton almost $40 \%$ of the high yield cattle elements and $21 \%$ of high yield pig elements had been processed when fresh. The number of high-yield cattle bones being processed rises to over $50 \%$ when just those present in the ring ditch are considered.

At the settlement site of Ludwinowo 7, fractures on high yield marrow bones were fresh in $62 \%$ of instances, and a very high level of fresh fracture that is reflected when looking more specifically at high yield cattle (69\%), pig (60\%) and wild (57\%) identifiable elements. These figures on high yield elements indicate an established tradition of intentional breakage of bones for marrow at Ludwinowo 7, and are similar to the proportions of fresh fracture on high yield bones found at Staines and on the high marrow yield cattle bone from the Etton ring ditch.

It is clear that there is some variation between the sites in terms of species and elements targeted for marrow extraction, and indeed there is also some variation from context to context. However, marrow exploitation appears to be a significant feature at all the sites at similar overall levels. Although evidence of this exploitation does not necessarily prove the presence of domestic activity at Staines and Etton or at causewayed enclosures more generally, it certainly adds to the growing body of 
evidence presented in this paper that indicates that economic activities were occurring on a more regular basis than has previously been assumed.

\section{Conclusions and discussion}

The original impetus for this research was to discover whether the animal bone assemblages at causewayed enclosure sites were genuinely distinct from what is thought to typify Neolithic domestic assemblages. The difficulty with reaching conclusions about this is that, in Britain, we still do not have a clear picture as to what a Neolithic domestic assemblage might look like, making it almost impossible to discern how causewayed enclosure assemblages might deviate. However, by comparing bone processing at Etton and Staines with the known LBK settlement site of Ludwinowo 7 in Poland, it is clear that the deviation in the nature of the animal bone assemblages and the bone processing identified thereon is not as significant as might be expected. In fact, at least with regards to levels of bone processing there is a great deal of similarity between the sites.

There is now a significant amount of evidence to suggest that bone fracture for marrow extraction was a common practice. Serjeantson $(2011,64)$ suggests that bones with single, central fractures may still be indicative of feasting and while this was seen at Etton, much of the assemblage was far more fragmented than this, suggesting the activity was rather more intense and potentially more indicative of non-feasting, domestic activity. The butchery evidence at Etton does not stand out as remarkable and would not be seen as out of place on a settlement site, especially if one accepts that there would not necessarily be a strict dichotomy between domestic and ritual activities at such sites in any case. Marks indicative of meat-removal were most prevalent, but whether this occurred before or after cooking cannot be said. Skinning marks were the least evident - but this likely does not reflect the absence of this process, just its ephemeral taphonomic signature. Disarticulation of carcasses was occurring regularly on all three of the primary domesticates, though there was more evidence on cattle. Some disarticulation marks present on the pelves of cattle, pig and caprines indicate the removal of the whole hind limb. For cattle and pig, disarticulation marks are also visible around the distal femur and proximal tibiae, suggesting further division of the carcass at this point, again potentially as a result of portioning activity. There were very few instances of the deposition of partial skeletons or of articulated limbs, which are sometimes given as evidence for feasting activity. 
It is very clear now that at Etton, fragmentary animal bone remains were abundant, and very occasionally a more complete set of remains was encountered. While some of these fragmentary remains were deposited in a seemingly purposeful manner, it is difficult to understand why it was that the animal bone assemblage was originally interpreted as not being 'typical of a domestic assemblage' (Pryor 1998, 361). With the exception of the a small overall number of bones and the selection of primarily small mammals, Etton conforms almost perfectly to Serjeantson's recent model for everyday consumption (Serjeantson 2011, 64). The vast majority of elements were found both disarticulated and fragmented, all parts of the carcass were represented (though lower numbers of peripheral bones have been recorded), burning is exceptionally rare at Etton, both on bone fragments of more complete bones, and marrow bones are often found in large fragments, rather than partial bones. However, the only two points on Serjeantson's model for feasting, to which Etton conforms, are an abundance of meat bearing elements and that there are large quantities of bone. Both of these points could point to the fact that large amounts of food were consumed at Etton over its use, but this does not necessarily mean that ceremonial feasting was the only type of consumption occurring here. It is very likely that communal consumption was an aspect of Etton's usage. However, this alone ought not to define how Etton was used as a causewayed enclosure. Such evidence for communal consumption is likely to be visible wherever Neolithic people were living, working and eating, and indeed it is highly likely that feasting activities were also a feature of life within the settlement of Ludwinowo 7.

It is suggested that a great deal further work is required to fully understand the nature of the economies of causewayed enclosures. The traditional view of the animal bone assemblages at Etton and Staines, and potentially therefore at other similar sites, must now be questioned. It is hard to understand why it is that so many are so adamant that the animal bones do not represent domestic activity. Rather, it is suggested (as has been suggested so often before) that the notions of ritual and domestic activity in the Neolithic are entirely devoid of meaning There is no reason to deny that causewayed enclosures might represent a snapshot of a part of the Neolithic economy that could well have encompassed both the sacred and the profane and, with the exception of intermittent 'atypical' deposits, it is currently impossible to disentangle the motives of deposition.

More generally, it is now also time revisit the separation between developments in material culture and economy, postulated graphically by Thomas (1999, Figure 2.1). 
His graph shows instant change in material culture at the start of the Neolithic and only very gradual change in economy, which only accelerates in the middle Bronze Age (remarkably, though presumably unintentionally, it also shows no change in material culture from the Neolithic to the Bronze Age). At the time this graph was drawn, it represented a very particular spin on the evidence available. The evidence base has since expanded considerably. In general, there is now considerably more evidence for settlements and the more regular recovery of environmental remains. There are now strong arguments that there is sound evidence for significant early Neolithic utilization of cereals (Jones and Rowley-Conwy 2007) at levels that provide evidence that is comparable with LBK settlements (Bogaard and Jones 2007). The data presented here are also benchmarked against an LBK comparator that similarly leads to the conclusion that faunal patterning relating to the processing of domestic animal carcasses differs little from LBK settlements. Most significantly of all, the development of methods for identifying lipid residues absorbed into pottery has demonstrated widespread exploitation of dairy products in the early Neolithic of Britain on both 'ritual' and domestic sites (Copley et al. 2003; 2005). Dairying represents an intensive form of cattle husbandry that was apparently present from the early stages of the Neolithic in Britain. Since this line of evidence directly ties Neolithic ceramic material culture to domestic economic products, the proposed separation of developments in these classes of evidence is directly refuted. Indeed, a new study (Cramp et al. 2014) that combines lipid residue analyses, faunal data and dietary isotope proxies demonstrates the immediate replacement of marine foods with dairy products by the earliest farmers in the Northern British Isles. This new work meshes well with some earlier isotopic studies (e.g. Richards 2003).

Both new scientific methods and closer scrutiny of traditional forms of evidence, along with better continental comparisons, all lead to the conclusion that economic interpretations of the Mesolithic/Neolithic transition and early Neolithic life in Britain need to be revised. In particular the role of causewayed enclosures might need further consideration.

\section{Acknowledgements:}

We wish to thank Francis Pryor, for both his blessing to revisit the Etton material, and the enthusiasm with which he has responded to the resulting research. Thanks are also owed to Richard Sabin at the Natural History Museum, for his help in accessing and processing the material from both Staines and Etton. We thank Richard Evershed and the rest of the NEOMILK team and are grateful to the ERC for funding 
that project (NEOMILK ERC324202). Our gratitude goes to Arkadiusz Marciniak for providing access to the Ludwinowo 7 material. We thank two anonymous reviewers for their useful comments.

\section{References:}

Albarella, U., and D. Serjeantson. 2002. A Passion for Pork: Meat Consumption at the British Late Neolithic Site of Durrington Walls. In Consuming Passions and Patterns of Consumption, ed. P. Miracle and N. Milner, 33-49. Cambridge: McDonald Institute.

Ammerman, A.J., and L.L. Cavalli-Sforza. 1971. Measuring the rate of spread of early farming in Europe. Man 6: 674-688.

Armour-Chelu, M. 1998. The Animal Bone. In Etton: excavations at a Neolithic causewayed enclosure near Maxey, Cambridgeshire, ed. F. Pryor, 271-278. London: English Heritage.

Bogaard, A., and G. Jones. 2007. Neolithic farming in Britain and central Europe: contrast or continuity? In Going Over: The Mesolithic-Neolithic Transition in NorthWest Europe. Proceedings of the British Academy 144, ed. A. Whittle and V. Cummings, 357-375. Oxford: Oxford University Press.

Bogucki, P. 1998. The antiquity of dairying in temperate Europe. Expedition 28(2): 51-58.

Copley, M.S., R. Berstan, S.N. Dudd, G. Docherty, A.J. Mukherjee, V. Straker, S. Payne, and R. P. Evershed. 2003. Direct chemical evidence for widespread dairying in prehistoric Britain. PNAS 100: 1524-1529.

Copley, M.S., R. Berstan, A.J. Mukherjee, S.N. Dudd, V. Straker, S. Payne, and R.P. Evershed. 2005. Dairying in antiquity. III. Evidence from absorbed lipid residues dating to the British Neolithic. Journal of Archaeological Science 32: 523-546.

Cramp, L.J., J. Jones, A. Sheridan, J. Smyth, H. Whelton, J. Mulville, N. Sharples, and R. P. Evershed. 2014. Immediate replacement of fishing with dairying by the earliest farmers of the northeast Atlantic archipelagos. Proceedings of the Royal Society B: Biological Sciences 281: 20132372. 
Cunliffe, B. 1992. Pits, preconceptions and propitiation in the British Iron Age. Oxford Journal of Archaeology 11: 69-84.

Edmonds, M. R. 1999. Ancestral Geographies of the Neolithic: Landscapes, monuments and memory. London: Routledge.

Gibson, A. 2003. What do we mean by Neolithic settlement? Some approaches, 10 years on. In Neolithic settlement in Ireland and Western Britain, ed. I. Armit, E. Murphy, E. Nelis and D. Simpson, 136-145. Oxford: Oxbow.

Grant, A. 1984. Animal husbandry. In Danebury: an Iron Age Hillfort in Hampshire. Volume 2. The Excavations 1969-1978: the Finds, ed. B. Cunliffe, 102-119. London: Council for British Archaeology.

Grigson, C. 1999. The Mammalian Remains. In The harmony of symbols: the Windmill Hill causewayed enclosure, Wiltshire, ed. A. W. R Whittle, J. Pollard and C, Grigson, 16-252. Oxford: Oxford University Press.

Harding, A., R. Šumberová, C. Knüsel, and A. Outram. 2007. Velim: Violence and Death in Bronze Age Bohemia. The Results of Fieldwork 1992-95, with a Consideration of Peri-mortem Trauma and Deposition in the Bronze Age. Prague: Institute of Archaeology Prague.

Harris, O. 2003. Performative practice: identity and agency at the causewayed enclosures of Windmill Hill and Etton. MA thesis, University of Cardiff.

Jones, G. 2000. Evaluating the importance of cultivation and collecting in Neolithic Britain and beyond. In Plants in Neolithic Britain and Beyond, ed. A.S. Fairbairn, 7984. Oxford: Oxbow.

Jones, G, and P.A. Rowley-Conwy. 2007. On the importance of cereal cultivation in the British Neolithic. In The Origins and Spread of Domestic Plants in Southwest Asia and Europe, ed. S. College and J. Conolly, 391-419. Walnut Creek: Left Coast Press. 
Johnson, E. 1985. Current developments in bone technology. In Advances in archaeological method and theory Vol. 8, ed. M.B. Schiffer, 157-235. New York: Academic Press.

Lüning, J. 2000. Steinzeitliche Bauern in Deutschland - die Landwirtschaft in Neolithikum. Bonn: Rudolf Habelt.

Morris, J. 2008. Re-examining Associated Bone Groups from Southern England and Yorkshire c. $4000 B C$ to $A D$ 1550. PhD thesis, University of Bournemouth.

Oswald, A., C. Dyer, and M. Barber. 2001. The Creation of Monuments: Neolithic Causewayed Enclosures in the British Isles. Swindon: English Heritage.

Outram, A.K. 2001. A new approach to identifying bone marrow and grease exploitation: why the "indeterminate" fragments should not be ignored. Journal of Archaeological Science 28(4): 401-410.

Outram, A.K. 2002. Bone Fracture and Within-Bone Nutrients: An Experimentally Based Method for Investigating Levels of Marrow Extraction. In Consuming Passions and Patterns of Consumption, ed. P. Miracle and N. Milner, 51-64. Cambridge: McDonald Institute.

Outram, A.K., C.J. Knüsel, S. Knight, and A.F. Harding. 2005. Understanding complex fragmented assemblages of human and animal remains: a fully integrated approach. Journal of Archaeological Science 32(12): 1699-1710.

Parker-Pearson, M. 2003. Food, culture and identity: an introduction and overview. In Food, Culture and Identity in the Neolithic and Early Bronze Age, ed. M. ParkerPearson, 1-31. Oxford: British Archaeological Reports.

Parker-Pearson, M. 2012. Exploring the Greatest Stonehenge Mystery. London: Simon and Schuster

Parker-Pearson, M., J. Pollard, C. Richards, J. Thomas, C. Tilley, and K. Welham. 2008. The Stonehenge Riverside Project: exploring the Neolithic landscape of Stonehenge. Documenta Praehistorica 7(410): 153-166. 
Parmenter, P.C.R. 2015. A Reassessment of the Role of Animals at the Etton Causewayed Enclosure. PhD Thesis, University of Exeter.

Pollard, J. 2001. The Aesthetics of depositional practice. World Archaeology 33: 2, 315-333.

Pryor, F. 1998. Etton: excavations at a Neolithic causewayed enclosure near Maxey, Cambridgeshire. London: English Heritage.

Pyzel, J. 2012. Preliminary results of large scale emergency excavations in Ludwinowo 7, comm. Włocławek. In Siedlungsstruktur und Kulturwandel in der Bandkeramik: Beiträge der internationalen Tagung "Neue Fragen zur Bandkeramik oder alles beim Alten?!", ed. S. Wolfram and H. Stäuble, 160-166. Dresden: Landesamt für Archäologie.

Richards, M. P. 2003. Explaining the dietary isotope evidence for rapid adoption of the Neolithic in Britain. In Food, Culture and Identity in the Neolithic and Early Bronze Age, ed. M. Parker Pearson. 31-36. Oxford: British Archaeological Reports.

Rowley-Conwy, P.A. 2000. Through a taphonomic glass, darkly: the importance of cereal cultivation in prehistoric Britain. In Taphonomy and Interpretation, ed. J.P. Huntley and S. Stallibrass, 43-53. Oxford: Oxbow.

Serjeantson, D. 2011. Review of Animal Remains from the Neolithic and early Bronze Age of Southern Britain (4000 BC - 1500 BC). Swindon: English Heritage.

Thomas, J. 1999. Understanding the Neolithic. London: Routledge.

Thomas, J. 2003.Thoughts on the `repacked? Neolithic revolution. Antiquity 77: 6774.

Thomas, J. 2004. Recent debates on the Mesolithic-Neolithic transition in Britain and Ireland. Documenta Praehistorica 31: 113-30.

Thomas, J. 2013. The Birth of the Neolithic. Oxford: Oxford University Press. 
Wait, G. 1985. Ritual and Religion in Iron Age Britain. Oxford: British Archaeological Reports.

Whittle, A.W.R. 2003. The Archaeology of People: dimensions of Neolithic Life. London: Routledge.

Whittle, A., and J. Pollard. 1999. The harmony of symbols: wider meanings. In The Harmony of Symbols: The Windmill Hill Causewayed Enclosure, ed. A. Whittle, J. Pollard and C. Grigson, 381-90. Oxford: Oxbow. 


\section{Figures}

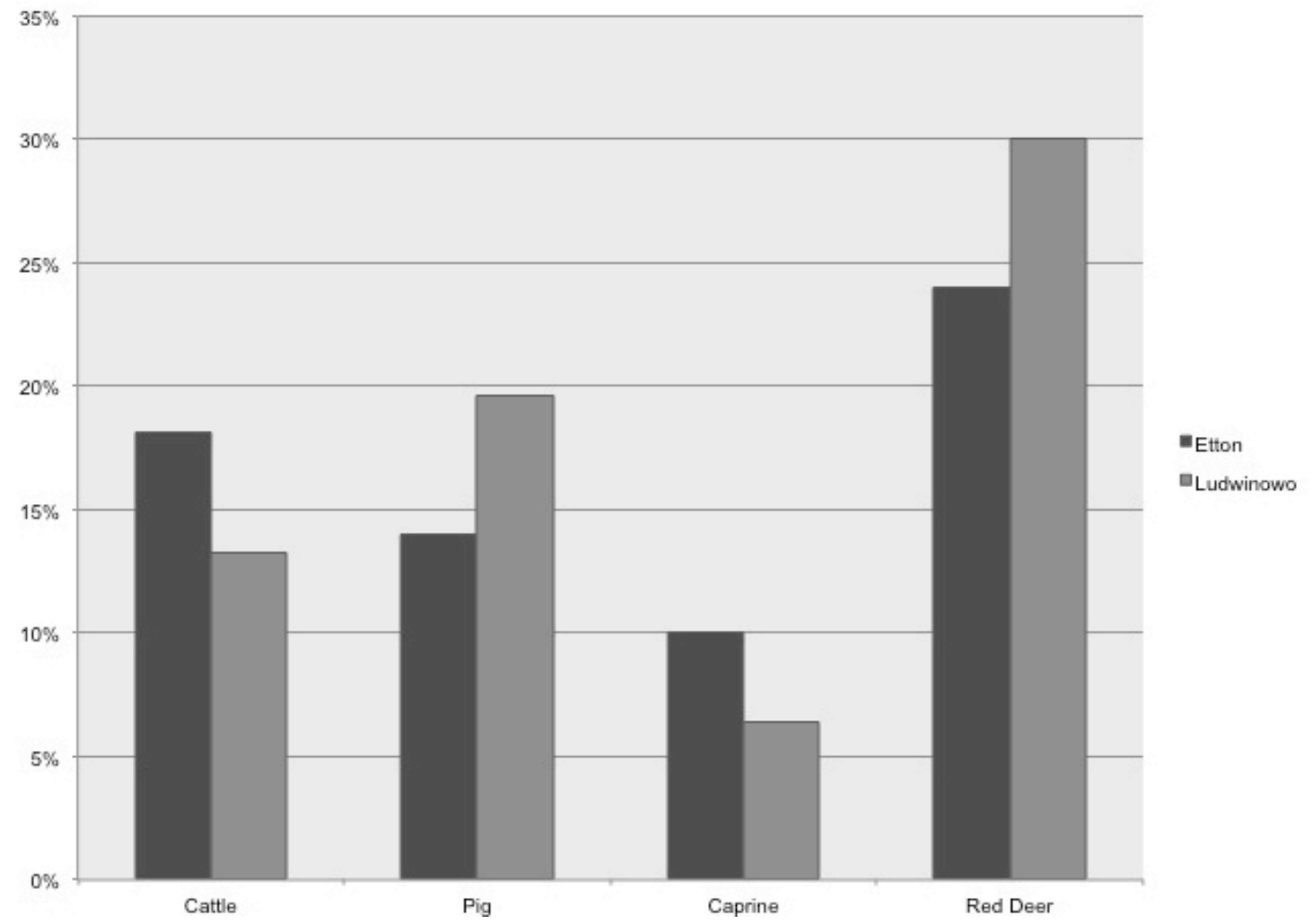

Figure 1: Comparison of percentages of identifiable specimens of different species displaying evidence of butchery marks

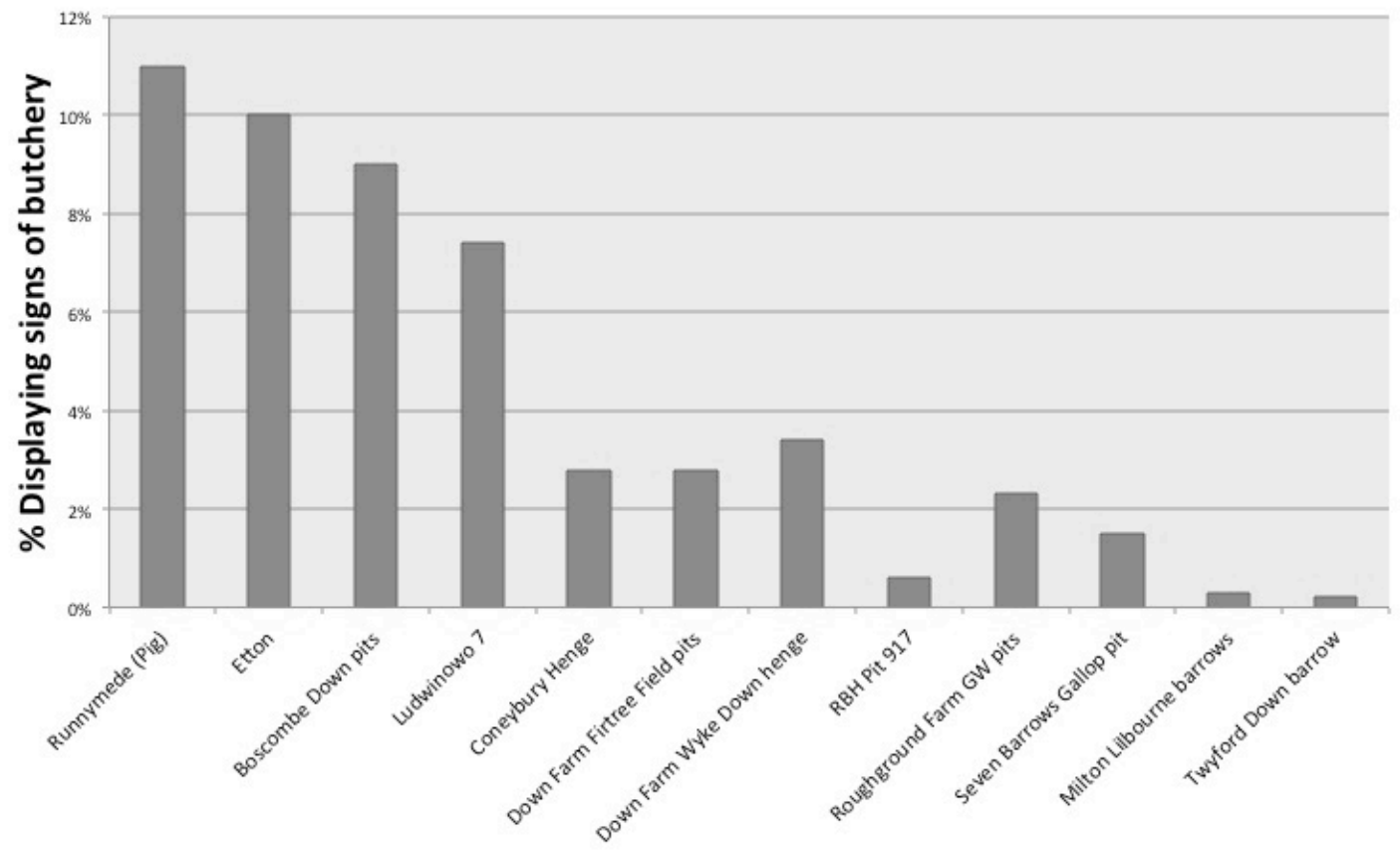

Figure 2: Percentage of identified bone specimens at different Neolithic sites displaying evidence of butchery. 


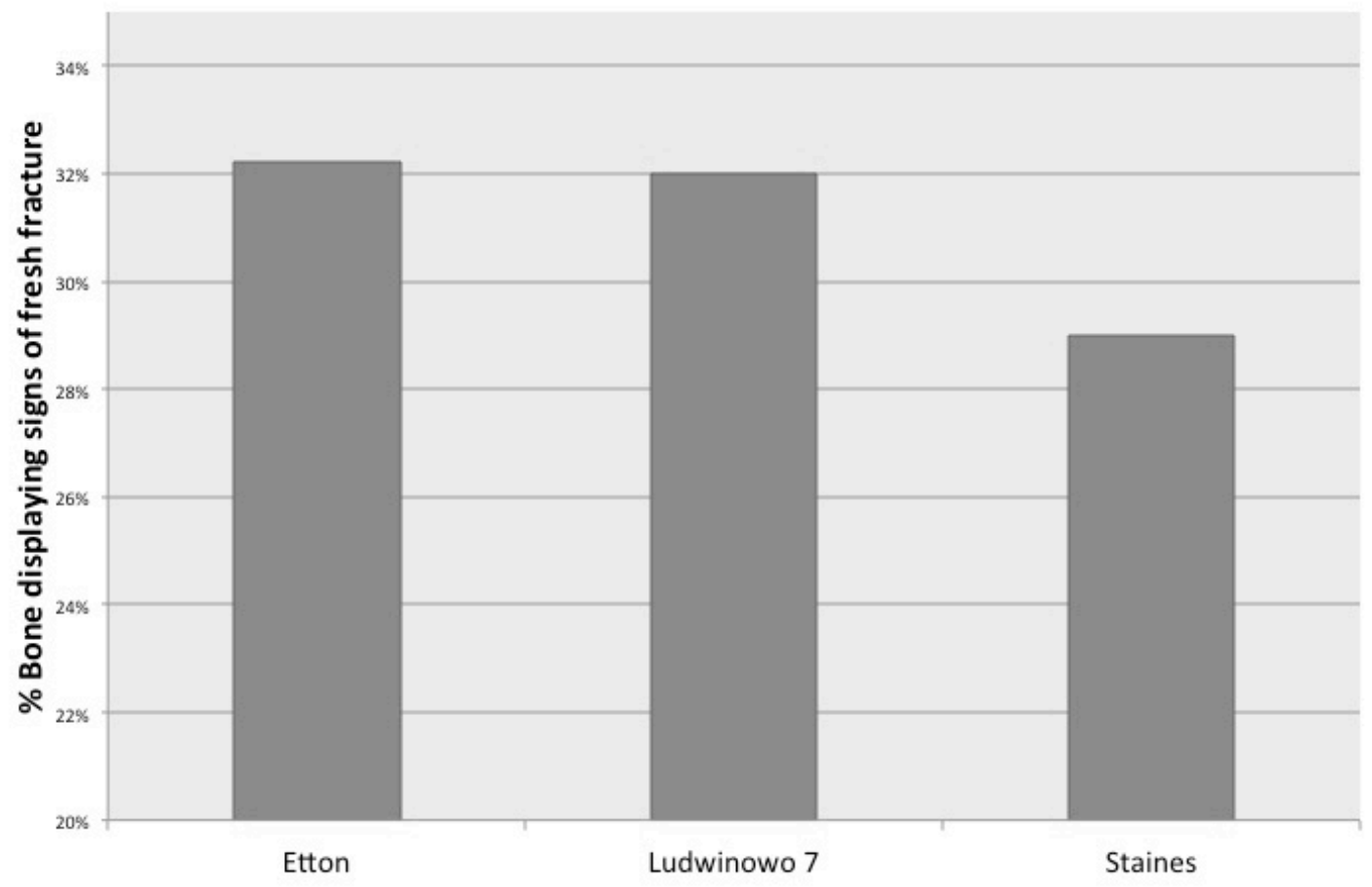

Figure 3: Percentage of identified bone specimens displaying signs of fresh bone fracture at the different sites 